\title{
Cluster cub: definition and structure
}

\author{
K.A. Grigorian \\ Associate Professor \\ Department of economic theory \\ Institute of Management, Economics and Finance \\ Kazan Federal University, \\ Kazan, 420008, Russia
}

\author{
V.V. Ryazanov \\ Graduate student \\ Department of financial management \\ Institute of Management, Economics and Finance \\ Kazan Federal University, \\ Kazan, 420008, Russia
}

\begin{abstract}
Global trends indicate the approach of the sixth technological structure, which will significantly affect the socioeconomic situation in the whole world, which may remake the global economy structure. The article is dedicated to research of a kind of structure changes, which will take place in the new technological structure and methods of reflection on it. The article is dedicated to research of the interregional interaction as one of basic factors of the economic efficiency in the sixth technological structure. In the work a hypothesis is put forward. Its idea is that industries with the bigger added value are more influenced by the level of interregional interaction. Interregional clusters are proposed as a measure of innovation process activation.
\end{abstract}

Keywords - six technological structure; interregional interaction; innovation economy; interregional cluster.

\section{INTRODUCTION}

It is announced that the 4th industry revolution is coming soon. It is estimated that the speed of revolution will be very fast and the impact of it on the world economy will be very significant. Countries which just started to develop the 5th technology structure face significant risks and may lose their economy and political positions. So it is very important for them to catalyze the innovation process as never before.

Nowadays the common approach to the economy growth and the innovation activity is the encouragement of competition. If we take the Russian Federation as an example we will see that its economy is considered as economies of its regions. There are two basic approaches to analyze the regional efficiency:

1. the estimation of the region input as an arithmetic contribution;

2. the estimation of the region input as a system unit.

The first approach estimate the efficiency of the region by comparison of its share in the country's production with its share in country's resources. The socio-economic efficiency is estimated as a comparison of the life level with expenditures undertaken [1].

The second approach estimates external effects of the region. One should to facilitate the interregional interaction by creating an appropriate economic motivation and destructing barriers between them [2]. In addition, there we should notice two contradictory points [3]:

- the some level of the inequality between regions stimulate the interaction between them;

- Too high level of the inequality between regions acts like a barrier of the region interaction.

There are two groups of inequality factors [4]. The first group consists of:

- the level of resources in a region;

- the geographical location.

The second group consists of:

- $\quad$ the agglomeration effect;

- $\quad$ the human capital;

- $\quad$ the infrastructure.

So to facilitate the interregional interaction, we should prevent the increase of the inequality of regions.

Inequality factors of the first group are not under our control, but they lose significance in the six technology structure. Therefore we should concentrate forces on factors of the second group.

One of the aspects of the interregional interaction is the resource allocation. There is a situation when one of regions need additional resources for the development and others have a surplus that can be allocated more efficiently by the transferring to others. This is obvious advantage of the interaction but we should take institutional factors into account. Regions are governed by different peoples, which has the region efficiency (not national) as a priority.

We suppose that the 4th industry revolution will require a lot of resources to transfer the country into the six technology structure. We suppose that industries with the bigger added value are more influenced by the level of the interregional interaction. So we made the factor analysis of 79 regions of the Russian Federation.

Using the least squares method, two regression models were constructed:

1. The influence of the interregional interaction on industries with the low added value level; 
2. The influence of the interregional interaction on industries with the high added value level.

As a factor variable we took the interregional import between 2010-2013. As a result variable we took the number of companies in different spheres as of 2014.

For the first model we took the number of companies in the agriculture, fisheries and mining operation.

For the second model we took the number of companies in the construction, manufacture and network.

As a result for the first model, we received the following regression model:

$$
C_{1}=1853,09+0,0006 * I,
$$

where:

$\mathrm{C} 1$ - the number of companies in the agriculture, fisheries and mining operation;

I - the import volume from other regions of the Russian Federation.

The adjusted coefficient of the determination for the model is 0.26 and it allow us to conclude that the interregional interaction has low impact on industries with the low added value level.

As a result for the second model we received the following regression model:

$$
C_{2}=4332,21+0,0129 * I,
$$

where:

$\mathrm{C} 2$ - the number of companies in the construction, manufacture and network;

I - the import volume from other regions of the Russian Federation.

The adjusted coefficients of the determination for the model is 0.89 and it allows us to conclude that the interregional interaction have significant impact on industries with the high added value level.

The further specification of the model shown is as the following regression:

$$
C_{2}=2710,57+0,0548 * A+1,5257 * M+33,4554 * P,
$$

where:

$\mathrm{C} 2$ - the number of companies in the construction, manufacture and network;

A - the import volume of the automobile industry;

$\mathrm{M}$ - the import volume of metallurgy industry;

$\mathrm{P}$ - the import volume of timber.

The adjusted coefficient of the determination for the mode is 0.96 . So we can conclude that the interregional interaction is very significant for the economy growth and its role increases with the increase in the level of the product complexity.
One of the main specific of the new technology structure is the interweaving of industries [5]. This is so called NBIC conception, which means the integration of nanotechnology, biotechnology, information technology and cognitive science [6]. The main challenge here is the differentiation in the development level of different industries. Under the six technology structure we have no more ability to develop biotechnology with the low level of the information technology and so on. Also we should notice that one of the basic strategies of some countries, regions was to choose a sphere of the specialization and to catalyze its development. Sciences also were developing separately from each other. The new technology structure requires performing integration of industries and the synthesis of sciences.

\section{RESULTS AND DISCUSSION}

The common method today to increase innovation activity is creation of clusters. Main their characteristics are [7]:

1. the common technology;

2. the territorial localization;

3. common resources.

These characteristics lose their significance in the six technological structure. Because the common technology is required to be replaced by the integration of technologies. The territorial localization and common resources lose its role because of the replacement material resources by more mobile resources (the human capital and information technologies). In the digital economy we have no more significant physical restrictions. In the new economy we should analyze a new characteristic - the institutional distance, which is a complex estimation of economic, legal and bureaucratic barriers between subjects in a market.

But there is an advantage to develop clusters: clusters concentrate resources and coordinate a work.

As a result we need to create the new mechanism of the acceleration of the innovative activity. We propose to create a cluster "Cubs", which planes are:

1. the interregional interaction;

2. the integration of industries;

3. the synthesis of science.

In the form of these panes in such 3D clusters, the government, the business and the academic community will be integrated.

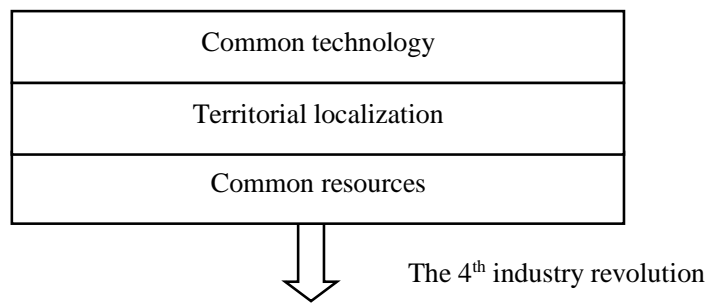




\section{Cluster cubes (3D cluster)}

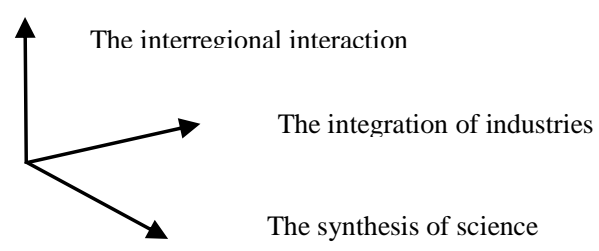

Fig. 1. The transition of the clusters conception

To analyze cluster cubes, we can draw the matrix of interaction (Table 1).

TABLE I. THE MATRIX OF INTERACTION

\begin{tabular}{|c|l|l|l|}
\hline & \multicolumn{1}{|c|}{ Authorities } & \multicolumn{1}{c|}{ Industry } & \multicolumn{1}{c|}{ Science } \\
\hline Authorities & $\begin{array}{l}\text { The } \\
\text { interregional } \\
\text { interaction }\end{array}$ & $\begin{array}{l}\text { The business and } \\
\text { government } \\
\text { partnership }\end{array}$ & $\begin{array}{l}\text { The } \\
\text { governmental } \\
\text { regulation of } \\
\text { science }\end{array}$ \\
\hline Industry & $\mathrm{X}$ & $\begin{array}{l}\text { The integration of } \\
\text { industries }\end{array}$ & $\begin{array}{l}\text { The academy } \\
\text { and business } \\
\text { interaction }\end{array}$ \\
\hline Science & $\mathrm{X}$ & $\mathrm{X}$ & $\begin{array}{l}\text { The synthesis of } \\
\text { science }\end{array}$ \\
\hline
\end{tabular}

Creation of a cluster should be started by specifying its basic elements such as:

- Goals of the cluster.

- Mechanisms of creation.

- The lifecycle of the cluster.

- The monitoring of cluster.

Goals of a cluster cube can be divided on two basic groups. The first group is the priority goal - the development of the technology of the six technology structure.

The second group consists of supplemental goals:

- The raise of the innovative companies share.

- The development of innovation companies, strengthening of their positions.

- The increase in the ratio of $\mathrm{R} \& \mathrm{D}$ materials realization on practice.

After describing cluster goals, we can conclude that it will be more appropriate to use the project management model to gain more efficiency.

The goal of the cluster is not a standard project realization, because results of the project and its boundaries are too difficult to predict. So one should implement the Agile approach in day-to-day cluster operating. The main principle of the Agile is the priority of final goods as a measure of the efficiency. Due to that the innovative process should provide prototypes of products in the short period of time. It makes us able to make corrections to the production process operatively.
One of cluster functions should be the digitization of business processes. There is a misunderstanding between those who provide digital goods and those who could embed it into the business.

So, there should be a special role in a cluster - digit mediators. They should be professionals, who understand sophisticated technical matters, on the on hand, and understand business processes of the client, on the other hand. These professionals should be able to calculate the budget and create the business plan of the digitization as well as hold tenders to choose better suppliers.

Besides digit mediators there should be other mechanisms to facilitate the process of the digitization. This facilitation can be of two different kinds: the supply support or the demand stimulation. The supply support can be implemented in the form of the subsidizing companies who provide digital services. The demand stimulation can be implemented in monetary or/and non-monetary forms.

These measures should be balanced and implemented in a very careful manner. It is the support supply which requires special attention because it can distort market mechanisms, lead to the unfair competition and finally case the decrease in the digit services quality. The supply support should be more oriented to non-monetary methods: the barriers destruction and the information support. Digital services suppliers should have full understanding about the amount and the kind of services required by the market. This is a work of digit mediators.

The demand stimulation is the goal of digit mediators as well. The demand can be stimulated by the subsidizing or budget crediting for projects of the digitization.

One of the faces of the cluster cube is the facilitation of the business and government partnership. In terms of the innovation development it can be analyzed in two basic directions: the partnership in development innovation goods and the partnership in the development the innovation infrastructure.

The partnership in the development of innovation goods unfold in funding high risk projects. Innovative projects are always high risk because of their unpredictable character. This risk can be a main reason to refuse to implement a project, which deprives the economy of some profitable projects.

Projects can be hedged in insurance companies, but insurance services for innovative projects can be too expensive; that is why there should be a system of the government funding or government insurance services.

The development of the innovative infrastructure is the long-term project and it has indirect return for the investor; that is why such kind of investments is not very attractive for the private sector, which is mostly aimed at short-term results.

The development of the innovation infrastructure consists of:

- the development of the human capital; 
- the development of the legislation in the field of the intellectual property protection;

- the development of the tax legislation to stimulate the innovation;

- the elimination of bureaucratic barriers to the innovation.

The development of the human capital is worth considering in the context of several aspects.

The first aspect is the development of a modern education system that will be able to train the highly qualified personnel from the younger generation. Special attention should also be paid to the development of a system of professional retraining, because changes in the field of the technology and, as a result, in the social and economic life occur with the ever-increasing speed. The lack of a retraining system will lead to a strong differentiation of the population and an increase in a social tension, which, finally, will negatively affect the social and economic development and the innovative development in particular.

The second aspect is that it is also the responsibility of the state to support the development of specialists in fundamental sciences, since the strategic importance of this direction cannot always be appropriately estimated by representatives of the private business, and this direction may be less priority in comparison with applied fields of the science.

The third aspect is the development of a system of flexible educational standards that will make it possible to change the educational process as quickly as possible while maintaining a balance of the quality and the relevance of the education received. The lack of flexibility in the educational process entails an increase in the opportunistic behavior of the students, which makes the learning process extremely inefficient. It is this aspect that implies the closest possible interaction of the academic environment with the business community. The business should fully and accurately communicate to the academic environment what knowledge and skills are now required in the labor market. This will allow educational institutions to adjust current educational programs and communicate their expectations to students. Trainees with greater motivation will absorb more applicable, understandable material, and will also more efficiently join the work process, having in advance sufficient knowledge of it.

The fourth aspect is the continuous professional development. An indicator of the current state of the system of the higher education is the availability of a large number of training programs, expanding in a chaotic manner. This is a natural reaction reflecting the desire of people to obtain additional skills and knowledge that they can not receive in the framework of the traditional higher education. Such reaction of the business community allows you to adapt as quickly as possible to changes in the surrounding reality. However, the absence of any control over the educational environment increases the risk that the quality of such trainings and supplementary training programs will be of poor quality.
The development of the legislation in the field of the intellectual property protection is one of the foundations of the innovation development. The intellectual property protection system should, first of all, protect interests of those who want to acquire competitive advantages, investing in the development of innovative activities. However, a certain mechanism should be developed that would allow other market participants to enjoy achievements of innovative development in order to maintain a competitive environment in the market and continue to develop new technologies based on achievements achieved.

The development of the tax legislation in order to stimulate the innovation activity is to create a preferential position for companies involved in the innovative development. The key point here is a fairly accurate description of the target group, which will be able to take the advantage of tax benefits. There is a rather high risk of fraudulent activities, when the innovation activity is only fictitious, for being classified as a preferential category of taxpayers. One of the methods of leveling this risk is the transition from the "preferential taxpayer" category to the "preferential activity" category. The key risk of the innovation is the uncertainty of results. With such uncertainty, the investor implements costs, the coverage of which is not guaranteed at all. In this regard, one of the options for tax incentives for the innovation can be the recognition of costs as losses in full at the time of their actual implementation. At the same time, it is possible to introduce such a concept as an "innovative asset" that would reflect the amount of money spent on the implementation of an innovative project. Upon the completion of the project and the confirmation of its commercial success, the innovation asset should be included in the tax base, possibly with a higher tax rate.

So, if we will consider the innovative policy applied to cluster cubs, we can describe it according to the each type of interaction.

The public private partnership in the cluster can be implemented by financing of digitization budgets, financing the work of digit mediums, the development of the infrastructure to reduce the institutional distance between cluster participants.

Private companies can interact with the academic society by holding internships, by the participation in the development of education standards, by developing centers of continuing education programs.

There are two types of the interaction which are of complex character and require even the triangular interaction: the synthesis of science, the integration of sciences and the interaction between academic society and the business. The interaction can be initiated in two different directions from the business to academic society and from the academic society to business.

There must be special teams of scientists who will seek the interdependence in different spheres of the science. Further, it will require implementing new knowledge in practice by engaging partners from the business society. 
Another direction will be required when the intersectoral business team will face the lack of a theoretical basic, which they will be required to eliminate to make the next step in the development.

And the other side of a cluster cube is the interregional interaction. Its purpose is to coordinate the regional activity in the sphere of the innovation to facilitate the achievement of the cluster's goal. The cluster should be entitled to perform some categories of actions with no sanction on it from local authorities.

All we need to say is that nowadays there is a lack of innovation mechanisms for the $6^{\text {th }}$ technical structure realities. We propose cluster cubs as a mechanism, which facilitate:

1. The interregional interaction.

2. The integration of industries.

3. The synthesis of science.

The cluster should function according to the Agile manifest to be more flexible and to provide more operative analysis of the current situation.

\section{References}

[1] V. V. Komarova, «Toolkit for assessing and analyzing the efficiency of the region's economy», Socio-economic phenomena and processes, 2013, pp. 1- 45

[2] T.I. Yas'kova, «Near the capital position as a factor of social and economic development of the Smolensk region», Synopsis, 2014.

[3] A.B. Gusev, «Evaluation of the influence of interregional economic inequality on macroeconomic growth», The science. Innovation. Education, 2011, no. 10, pp. 102-110.

[4] N.V. Zubarevich, S.G. Safronov, «Inequality of socio-economic development of regions and cities of Russia in the 2000s: growth or decline?», Social sciences and modernity, 2013, no. 6.

[5] S. Manukov, «The 4th Industrial Revolution in Davos», Electronic publication "Expert Online", 01/21/2016.
[6] D.P. Frolov, M.M. Babkin, «NBIC-convergence: the regional dimension», Regional economy: theory and practice, 2016.

[7] N.A. Yastreb, «The fourth industrial revolution: industrial networks ambiente intelligence», Innovation politics and economics, 2014, no. 4, pp. 22-26.

[8] L.G. Melnyk, I.B. Degtyareva, A.V. Kubatko, «The third industrial revolution as the way to sine economy», Materiel of the International Scientific and Practical Conference named after professor Balatskii O.F., 2016, pp. 45-46.

[9] L.G. Melnyk, «Innovation perspectives of the third industrial revolution: economy, energy, ecology», Marketing and management of innovations, 2016, no. 4, pp. 342-352.

[10] S.A. Tolkachev, A.D. Kulakov, « Neoindustrialization as a new technotronic economy (on example of robotics industries in U.S.A.), Part 1», Industry politics, 2015, no. 4, pp. 69-76.

[11] V.S. Kudryashov, «Cluster form of Russian economy organization», Juvenis scientia, 2017, no. 7, pp. 15-18.

[12] T.V. Uskova, E.B. Lukin, Interregional interaction as a factor of economic growth: preprint, Vologda, ISERT RAN, 2013

[13] E.V. Lukin, "Interregional interaction in the system of economic development of regions: theoretical and practical approaches», Territory Economics, 2013, no. 5 .

[14] A.G. Granberg, V.I. Suslov, S.A. Suspitsyn, «Economic and mathematical research of multi-regional systems», Region: Economics and Sociology, 2008, no. 2-12.

[15] S.G. Avdonina, «Quantitative methods for assessing the synergistic effect of an innovative cluster», Management of economic systems. Electronic scientific journal, 2012, no. 3.

[16] I.N. Garkin, I.A. Garkina, I.V. Markelova, «Implementation of Cluster Policy: Increasing the Competitiveness of the Region's Economy», Modern Problems of Science and Education, 2014, no. 2.

[17] S.Yu. Glazyev, V.V. Kharitonov, «Nanotechnology as a key factor in the new technological order in the economy», Monograph, 2009.

[18] Yu.V. Korechkov, O.V. Dzhioev, «Synergetic effect of integration processes and investment multiplication in integrated organizations», Internet-journal «Naukovedenie», 2015, no. 2.

[19] R.R. Akhunov, «Development of interregional integration as an improvement of competitiveness in the system of reproduction potential of the region», Bulletin USUES. Science, education, economy, Series economy, 2016, no. 1, pp. 7-16. 